\title{
TEOLOGIA E CORPOREIDADES QUEER EM DEBATE: UM FLÂNEUR POSSÍVEL?
}

\author{
Herlan José da Silva Smith* \\ Taíssa Tavernard de Luca**
}

\begin{abstract}
RESUMO
Entendendo o verbo francês flâneur a partir da perspectiva de Baudelaire, isto é, como uma pessoa que transita pelos meandros citadinos a fim de experienciá-los, este breve ensaio apropria-se do verbete mencionado para propor uma reflexão sobre as possibilidades de passeio e de comunicação entre teoria queer e discurso teológico, enquanto diálogo epistemológico que procura problematizar tanto a não normatização de corpos em identidades hetero-cis-sexualizadas, quanto o entendimento de se pensar sempre em teologia no plural. Aqui, após um percurso itinerário de influências, busco apontar brevemente para uma vertente na qual o passeio das subalternidades é, ao mesmo tempo, subversão para o pensamento teológico hegemônico e liberdade religiosa para corpos abjetos.

Palavras-chave: Teologia. Teoria queer. Teologia Queer.
\end{abstract}

\section{THEOLOGY AND CORPOREALITIES QUEER IN DEBATE: A POSSIBLE FLÂNEUR?}

\begin{abstract}
Understanding the french verb flâneur from the perspective of Baudelaire, as a person who transits through the urban sinuosity in order to experience the, this brief essay appropriates the mentioned verb to propose a reflection on the possibilities of walking and communication between queer and theological discourse. While epistemolo-
\end{abstract}

* Mestrando pelo Programa de Pós Graduação em Ciências da Religião da Universidade do Estado do Pará (UEPA). Possui graduação em bacharelado em Serviço Social pela Universidade da Amazônia (UNAMA).

** Doutora em Ciências Sociais pela Universidade Federal do Pará (UFPA). Mestra em Antropologia pela Universidade Federal de Pernambuco (UFPE). Professora Ad3 de Antropologia do curso de Licenciatura em Ciências da Religião e do Programa de Pós-Graduação em Ciências da Religião da Universidade do Estado do Pará (UEPA). 
gical dialogue that seeks to problematize both the normmatization of bodies in hetero-cis-sexualized identities and the understanding of always thinking in plural theology. Here, after an itinerary of influences, I try to point briefly to a slope where the tour of the subalternities is at the same time a subversion for hegemonic theological thinking and religious freedom for abject bodies.

Key-words: Theology. Queer Theory. Queer Theology.

\title{
TEOLOGÍA Y CORPOREIDADES QUEER EN DEBATE: UN FLÂNEUR POSIBLE?
}

\begin{abstract}
RESUMEN
Entendiendo el verbo francés flâneur a partir de la perspectiva de Baudeleire, esto es, como una persona que transita por los meandros de la ciudad con el fin de experimentarlos, este breve ensayo se apropia del verbo mencionado para proponer una reflexión sobre las posibilidades de paseo y comunicación entre la teoria queer y el discurso teológico, como diálogo epistemológico que busca problematizar tanto la no normatización de cuerpos en identidades hetero-cis-sexualizadas, así como el entendimiento de pensar siempre en teología en el plural. Aquí, después de un recorrido itinerario de influencias, busco apuntar brevemente a una vertiente donde el paseo de las subalternidades es al mismo tiempo subversión para el pensamiento teologico hegemônico y libertad religiosa para cuerpos en abyección.
\end{abstract}

Palabras clave: Teología. Teoría Queer. Teología Queer.

\section{DAS PRELIMINARES}

Os estudos queer, com outras vertentes de estudos contemporâneas, por exemplo, a epistemologia feminista e os considerados - durante a década de 1960 - estudos gays e lésbicos, causaram nos últimos anos novas políticas para se pensar tanto a identidade, como também o conhecimento. Provocaram novos modos de refletir, de experimentar e de contraditar a posição execrada destinada, nesse caso, as dissidências sexuais e de gênero historicamente, articulando análises que desconstroem posições de poder e questionam (não) lugares. É possível articular tais saberes a campos tradicionalmente disciplinadores e normativos como o da teologia? Em que medida os estudos queer têm 
perspectivado assombrar a forma como se empregam os discursos teológicos hegemônicos? É possível um transitar queer na teologia? Esses são alguns dos questionamentos que se ousam ensaiar aqui.

Muito se fala em teologia queer hoje em dia, apesar de todos esses empreendimentos ainda estarem, como bem aponta André Musskopf (2005), guardados nos armários das universidades, de seminários, nos armários das bibliotecas e de muitas editoras que ousam publicá-los. É pertinente reivindicar a cidadania religiosa para uma gama de possibilidades corpóreas que são ejetadas dos espaços físicos e simbólicos judaico-cristãos. Zonas que se cristalizaram no que Judith Butler (2003) cognomina de matriz heterossexual, que regula vidas humanas, instituições e relações sociais a partir da heterossexualidade compulsória e, por que não dizer, também na maneira pela qual os discursos teológicos mais ortodoxos lidam com a sexualidade e o gênero?

A proposta que tento apresentar aqui propõe um caminho diferente. Muitas das pesquisas sobre teologia queer ou teologia gay/inclusiva, em especial André Musskopf (2003, 2005, 2008) e Carlos Lacerda Coelho Junior (2012, 2014), empenham-se na perspectiva de problematizar a vivência teológica de pessoas dissidentes sexuais e/ou de gênero e, a partir daí, trabalhar as potencialidades de um discurso teológico a la queer. Em alguns trabalhos, é até possível verificar um entendimento equivocado que compreende teologia queer como sinônimo de teologia gay. O dispêndio que ouso lograr aqui propõe caminho inverso: pretendo partir dos estudos queer em direção a uma crítica teológica. E, para lograr as possibilidades de passeio dos estudos queer em uma vertente teológica que afague as corporalidades abjetas, tento delimitar um percurso de influição até esse encontro.

Em primeiro momento, aponto para a influência e a intervenção do discurso feminista no mundo acadêmico ocidental e o seu empreendimento em reorganizar o conceito de gênero em uma pegada relacional. Em seguida, atenho-me, brevemente, para a atuação dos movimentos homossexuais de vanguarda, pois ambos promovem a emergência de uma teoria queer. Posteriormente, apresento o pensamento queer e algumas de suas nuanças características para, em último plano, partir dele em um flanar estranho em direção à teologia, rogando suas possi- 
bilidades e anseios na tentativa de expressar nas entrelinhas que essa associação é tanto uma neoforma teológica, o que por conseguinte materializa crítica para reflexões que enquadram teologia de modo uno, hegemônico e estritamente confessional, quanto um modus operandi, que questiona o lugar para corpos abjetos no seio da tradição judaico-cristã, ainda que esta, historicamente, tenha se construído enquanto não-lugar para as ditas e aqui chamadas corporeidades queer.

\section{AS FORÇAS MOTRIZES}

1.1 Influência do discurso feminista no mundo acadêmico ocidental ou sobre como passamos a ver gênero (de forma relacional) por elas

Tem se tornado mais habitual enxergar debates sobre gênero, sexualidades e feminismos dentro dos espaços acadêmicos, pois passamos a tomar, de acordo com Pedro Paulo de Oliveira (1998), as relações de gênero como parâmetros centrais no cotidiano da vida social, já que estas atuam como elementos fundantes na organização das vidas humanas, bem como, das instituições. Não deixando de lado os dispositivos de classe e de raça, as relações de gênero/sexualidade, respectivamente com eles, conforme o autor, compõem um tripé analítico que nos ajuda a compreender os meios pelos quais poder e recursos são socialmente construídos.

Mas é necessário entender que esse empreendimento tem uma história e que não nasce a qualquer preço, mas para pôr alguns discursos fora de ordem ou pelo menos da ordem que estrutura hierarquias de dominação entre homens e mulheres. Há de se reconhecer que o avanço dessas empreitadas, dentro dos meios acadêmicos, deu-se em função do potencial envolto ao discurso feminista, uma vez que, segundo o pensamento de Joan Scott (1989), a epistemologia feminista, a partir da década de 1980, começa a utilizar a palavra gênero com um caráter mais sério, passando a atribuir a esta categoria uma referência à organização social da relação entre os sexos e não mais uma mera forma de atribuição às mulheres ou aos estudos que se voltavam ao sexo oprimido. Nesse sentido, conforme Pedro Paulo de Oliveira (1998), a díade relacional - masculino/feminino - passou a possuir lugar de destaque dentro das discussões sobre gênero nos espaços acadêmicos. 
Antes da ressignificação conceitual do gênero enquanto categoria relacional, promovida pelo discurso feminista, Oliveira pontua que, se por um lado as mulheres levantavam a temática dessas relações como algo a ser pensado dentro e fora dos meios acadêmicos, por outro lado, na contramão desse esforço, "[...] costumava-se a tratar os homens como se eles não tivessem gênero" (Pedro Paulo de OLIVEIRA, 1998, p. 1), pois em suas alçadas e no seu uso mais simples, antes da apropriação feminista, gênero era tido como um sinônimo de mulheres, afirma Joan Scott (1989).

É assim que Joan Scott (1989) problematiza também a forma como gênero enquanto categoria foi utilizada historicamente de modo equivocado antes da apropriação epistemológica feminista nos espaços acadêmicos no decorrer dos anos 80 . O que a autora levanta e propõe a pensar em sua análise é que, se outrora o conceito de gênero ora se configurava como uma forma de atribuição as mulheres ou nos espaços acadêmicos um modo de referir-se aos estudos relativos ao sexo oprimido, toda a história e a produção acadêmica desenvolvida antes da apropriação feminista mediante ao conceito invisibilizou a participação das mulheres em ambos os setores.

Questionando-se a despeito dessas nuanças, Michelle Perrot (2007) lançava perguntas polêmicas à época, e uma delas se encaixa nesta problemática: qual o significado de escrever a história das mulheres, quando elas mesmas foram sucumbidas a silêncios impostos? Não é intenção responder tal questionamento, mas pensar, a partir do pensamento de Margareth Rago (1998), e reconhecer que muito se perdia nessa historiografia que não se deu conta de pensar as dinâmicas das relações sexuais/sociais.

Por isso, a epistemologia feminista ou os estudos feministas, como também é conhecida, pode ser definida, como bem apontou Francine Descarries (1993), um campo interdisciplinar que propõe produção de conhecimentos por meio do apelo de instrumentos conceituais, bem como, de problemáticas, no fito de analisar o que a autora chamou de "dimensões sexuadas das relações sociais". Logo, não se trata de estudos relacionados, unicamente, às mulheres, mas como uma produção que pensa sobre "[...] os efeitos estruturantes dos processos sociais 
sexuados em todas as dimensões do social e visam a uma transformação em profundidade das relações sociais, assim como de nossa própria maneira de pensá-las e de dizê-las" (Francine DESCARRIES, 1993, p. 58).

Assim, em certo grau, os estudos feministas provocaram uma revolução no meio acadêmico e na forma de se pensar a realidade cotidiana. Talvez seja possível afirmar que a empreitada que ousaram estabelecer na produção de conhecimento do mundo ocidental atua no processo de romper com o que Michelle Perrot (2007) chamaria de silêncio das fontes, justamente, porque refletindo sobre esse silenciamento na historiografia, a autora diria: "as mulheres ficaram muito tempo fora desse relato, como se, destinadas à obscuridade de uma inenarrável reprodução, estivessem fora do tempo, ou pelo menos, fora do acontecimento. Confinadas no silêncio de um mar abissal" (Michelle PERROT, 2007, p. 16).

Sobre o que chamou de o nascimento de uma história das mulheres, Michelle Perrot (2007), buscando averiguar o processo de institucionalização do pensamento feminista nas ciências humanas, afirma que esse evento se estabelece durante a década de 1960, primeiramente, segundo ela, na Grã-Bretanha, Estados Unidos e, uma década posterior, na França, por intermédio de diferentes fatores imbricados uns aos outros. Fatores esses científicos, sociológicos, políticos, os quais se sustentam na década seguinte com a crise dos sistemas de pensamento.

É desse modo que, de acordo com Margareth Rago (2012), os estudos feministas atuam dentro da produção de conhecimento, produzindo, segundo suas análises, uma crítica ao modo dominante de produção de conhecimento científico, como também apontando para um modo alternativo de operar e de articular nessa esfera, na busca do que chamou de nova linguagem e na produção de um contradiscurso. Pelo que brevemente fora discutido nesse primeiro momento, a reorganização do conceito de gênero foi esforço de epistemologias feministas contra discursos hegemônicos, que pode ser pensado a partir da visão da autora como um empreendimento que promove denúncia contra uma racionalidade operante em um campo ensimesmado, ou seja, por meio da lógica da identidade que não dá conta de pensar a diferença a partir de uma perspectiva relacional dentro do que se costumou chamar de ciência. 


\subsection{As primeiras pinceladas da paleta arco-íris: estética da existên- cia dos ativismos GGGs $^{1}$}

Assim como os feminismos dentro e fora dos espaços acadêmicos auxiliaram no modo de enxergar o gênero a partir do outro lado da moeda, nesse processo itinerário também se encontram os dispêndios teórico-políticos advindos do que se chamava estudos gays e lésbicos ou dos movimentos homossexuais durante a década de 1960, começando a dar visibilidade aos debates sobre o que se pode chamar de sexualidades periféricas, isto é, sexualidades fora do escopo basilar heterocentrado. Ambos influenciaram fortemente em demandas que culminaram no florescer de uma teoria queer e, posteriormente, em uma teologia queer.

Durante a década de 60, segundo Guacira Lopes Louro (2001) o movimento homossexual ganhava mais força a partir de grupos organizados, que promoviam reuniões de discussão e de ativismo. Não há como precisar e/ou comprovar essa colocação em sua integralidade, mas há que se reconhecer que muitas das pesquisas durante esse contexto que versavam sobre sexualidades não heterossexuais, ainda que com algumas deficiências discursivas atreladas ao próprio momento histórico, reverberam-se da militância de pesquisadoras e de pesquisadores que logravam suas lutas também no interior do universo acadêmico.

Hoje, conhece-se o movimento com acréscimo de algumas letras a mais que aludem para identidades específicas, mas nem sempre foi assim. O não reconhecimento do que Regina Facchini (2002) poderia intitular de sopa de letrinhas, lá atrás, tem suas justificativas. Aqui, aponto para duas respectivas possibilidades hipotéticas: 1 . Limite discursivo sobre diferença/cisão entre orientação sexual e identidade de gênero, que é uma compreensão mais contemporânea; 2 . Sobreposição dos valores de uma sociedade homogeneizante, que reconhecia todas as identidades sexuais e de gênero do movimento de forma igualitária. Tudo isso, fez que as pautas teórico-políticas se voltassem a um denominador comum em meio a esse contexto.

Movimentos GGGs é um termo êmico da militância LGBT atual que se refere à sobreposição das demandas "gays" em detrimento da invisibilidade das reivindicações das outras identidades. A utilização em sequência da letra "G" fazendo alusão à palavra "LGBT" é uma forma irônica de acentuar tal crítica no interior das ações coletivas que fazem esse recorte de sexualidade e de gênero. 
Esses movimentos homossexuais, nos Estados Unidos e na Europa, de acordo com as premissas de Richard Miskolci (2011), homogeneizavam-se na perspectiva política que se centrava no que chamavam de liberação sexual, dentro da qual a ação de sair do armário e a aceitação social para um estilo de vida essencialmente gay constituía-se enquanto pauta e realização máxima. Em outras palavras, era um dispêndio que tinha como finalidade uma adaptação ao meio. O autor adverte para a possibilidade de existência de diferentes propostas e de discussões, tanto no movimento social como na academia, mas na vida cotidiana era expressiva a necessidade de incorporação social, e esses rogos, segundo suas análises, "tinham apelo para uma juventude de classe-média ou alta, branca e universitária que colhia - primeiro e melhor - os resultados da despatologização e da descriminalização da homossexualidade nos países centrais" (Richard MISKOLCl, 2011, p. 47-48).

Segundo Carlos Lacerda Coelho Junior (2014), durante as décadas de 50/60, um novo florescimento acontece quando os grupos homossexuais começavam a se organizar nos Estados Unidos, mas na mesma perspectiva relatada outrora, buscando igualdade, tolerância, e advogando em defesa de que seria possível a incorporação das sexualidades não heterossexuais no seio de uma sociedade hegemonicamente heteronormativa. É nesse sentido que Richard Miskolci (2012) também destaca que essa tentativa reconciliadora desses movimentos era representada pelos preceitos de uma classe média, letrada e branca, ensandecida por aceitação.

Apesar de romper com posições teóricas equivocadas e preconceituosas que vieram antes, sobretudo com os saberes médicos e psi, Peter Fry (1982) dando um lugar de destaque para a homossexualidade na antropologia social e na sociologia, transcende posição semelhante às demandas de incorporação social dos movimentos homossexuais (já citadas) em sua produção, o que não desqualifica o seu legado. Isso fica expresso no título do capítulo IV de seu Para Inglês ver - Identidade e política na cultura brasileira, intitulado Da hierarquia à igualdade: a construção histórica da homossexualidade no Brasil, justamente, porque o discurso da igualdade é bem projeção de uma sociedade que se vê de forma homogênea. Era por meio do slogan "somos todos iguais", 
que os movimentos homossexuais de vanguarda tentavam se sucumbir ao que Judith Butler (2015) poderia chamar de enquadramentos ${ }^{2}$ das dinâmicas heteronormativas impostas em seus corpos, nas relações, nas instituições sociais.

Mas todo um cenário propiciou para a emergência desse pensamento nos movimentos GGGs de vanguarda. Toda essa necessidade de se afirmar ao lado da suposta normalidade sexual e de ser afagado pelas culturas heterocentradas, na perspectiva aqui adotada, remonta o cenário da década de 1980 em meio à pandemia de HIV/AIDS no mundo. Tudo isso, porque, em meio a esse cenário, as homossexualidades eram (re)patologizadas pelos preceitos morais de uma sociedade que associava a gênese do vírus da imunodeficiência humana a corpos não heterossexuais. O HIV, nesse contexto, era o câncer gay e a imagem do adoecido sempre era associada aos praticantes das relações estéreis.

Richard Miskolci (2011) discute a possibilidade de esse fenômeno ter sido um divisor de água na história contemporânea com entraves jamais superados no que chama de "esfera político sexual", justamente, porque, segundo suas análises, a epidemia transformou não apenas o cenário da época, mas impulsionou transformações culturais que sepultaram - até hoje - as tímidas vitórias da então chamada revolução sexual, pois na perspectiva que adoto aqui, o empreendimento de reforçar o que Erving Goffman (1975) intitularia de estigma na imagem do adoecido por AIDS às vivências fora da norma sexual estabelecida, foi um mecanismo usado para tornar esses corpos dóceis, como em Michel Foucault (1987), o que provoca, em certo grau, a desmobilização desses movimentos.

Foi circundando esse contexto de proliferação em massa de HIV no mundo que os movimentos homossexuais de vanguarda atuaram politicamente para reivindicar igualdade e não estimular a sociedade a exercitar alteridade, equidade ou aprendizado pelas diferenças, isto é, a tentativa

Termo utilizado por Butler (2015) em seu Quadros de guerra: quando a vida é passível de luto?, emprestado da teoria do enquadramento formulada pelo sociólogo Erving Goffman. Refere-se às molduras pelas quais apreendemos ou, na verdade, não conseguimos apreender a vida dos outros como perdida ou lesada (suscetível de ser perdida ou lesada) estão politicamente saturadas. 
de encaixar a homossexualidade dentro dos preceitos de uma matriz heterossexual, moldou a existência desses movimentos de vanguarda.

É nesse cenário conturbado que o queer - em contraposição à ordem sexual/gênero vigente e com uma posição diferente a dos movimentos homossexuais que se agitaram a partir da década de 60 - começa a ser esboçado. Tentou-se, por meio desta breve reflexão apontar as nuanças políticas que esses movimentos de vanguarda emanavam como que em um relapso itinerário: Primeiro os movimentos de mulheres dentro e fora da academia - organizando o conceito de gênero, que influenciou boa parte das análises, em especial na teologia, e aqui, o até então chamado movimento homossexual da geração desbunde dando as primeiras pinceladas na paleta arco-íris: pinceladas que não criticavam o status quo, não reconheciam uma multiplicidade de identidades, mas que tinham como objetivo enquadrar-se nas possibilidades de normalidade estabelecida pela suposta hegemonia sexual, o que pode definir, timidamente, a sua estética da existência nesse período. Em seguida, tento reproduzir a gênese e as características de uma teoria deslocada.

\section{EMERGÊNCIA DE SABERES SUBALTERNOS}

Donna Haraway (2009), em seu manifesto ciborgue, por intermédio de uma figura discursiva promove uma crítica feminista ao modo de se pensar a identidade, bem como, os efeitos do uso da tecnologia para as não tão ficções da realidade social que problematiza. Inicio essas primeiras linhas remetendo-me a essa referência, pois mesmo não tendo se reivindicado por meio desse posicionamento teórico, a razão ciborgue que a autora materializou, originalmente em 1985, fomentou muitas análises dentro do que se costumaria chamar de queer theory, uma vertente do pensamento que ousa habitar, assim como a figura híbrida - humano-máquina - da autora, um mundo pós-gênero ou na melhor das hipóteses, proclamar vivência em que os sistemas de regulação sexo/gênero, prática sexual/desejo, apontados por Judith Butler (2003), sejam notas para a subversão do que Paul Beatriz Preciado (2011) quiçá chamaria de política das multidões queer. Em suma, nessa linha de raciocínio, essa vertente de pensamento e ação política assume uma posição ciborgue, pós-identidade. 
Guacira Lopes Louro (2007) dissertando sobre conhecer, pesquisar e escrever na perspectiva pós-estruturalista, afirma que discussão e dissenso podem ser um modo de brandir o estabelecido, podendo ser (talvez) uma contribuição para a mudança nas convenções e nas regras impostas, bem como, um jeito criativo de lidar com a produção de conhecimento. Trago mais esta passagem, pois, quiçá, esse empreendimento esteja imbricado com o papel e a emergência do queer tanto em termos de produção de conhecimento, isto é, enquanto teoria, quanto em forma de movimento político, uma vez que este surge por meio das premissas de Richard Miskolci (2012) como impulso crítico à ordem sexual contemporânea, no seio dos manifestos de contracultura e das demandas dos chamados novos movimentos sociais na década de 1960 .

Mas afinal, o que é o Queer? Annamarie Jagose (1996) inicia o seu Queer theory - an introduction apontando para o queer em duas perspectivas: um termo guarda-chuva para identidades sexuais marginais e como nomenclatura para uma vertente de pensamento que tem origem nos antigos estudos lésbicos e gays, ambos ressignificados:

O termo "queer" era, na melhor das hipóteses, uma gíria para homossexuais, na pior delas, um termo de abuso homofóbico. Nos últimos anos, "queer" passou a ser usado de forma diferente, às vezes como um termo guarda-chuva para uma coalizão de auto-identificações sexuais culturalmente marginalizadas e outras vezes para descrever um modelo teórico recente, desenvolvido a partir dos tradicionais estudos gays e lésbicos (Annamarie JAGOSE, 1996, p. 1).

Por intermédio de Richard Miskolci (2012), vale ressaltar que queer era um xingamento, uma palavra de baixo calão, era um termo de ofensa utilizado para se referir, segundo o entendimento de Larissa Pelúcio (2014), às identidades sexuais e/ou de gênero que não se enquadravam na lógica da heterossexualidade compulsória. Queer, em nosso cotidiano, podia ser bicha, viado, boiola, sapatão. Era ofensa, injúria em forma de rótulo que definia e subjugava alguns corpos. É nessa direção que Guacira Lopes Louro (2006) afirma que tal expressão repetida como xingamento durante a história torna-se um enunciado performativo que fez e faz existir aqueles sujeitos a quem nomeia. Performativamente 
falando, instituindo posição marginalizada, execrada, uma posição indesejada.

A proposta - do movimento e da teoria - foi de reverter essa posição, mas sem sair dela. Em outras palavras, a ação estabeleceu-se em retirar a carga negativa por trás do termo e assumir o queer enquanto condição, marca ou posição, que nas palavras de Guacira Lopes Louro (2006) não se pretende fixar. Ao tornar-se marca discursiva para nomear uma série de produções de conhecimento e também, um posicionamento político, queer se inclina contra as "convenções culturais como forças autoritárias e preconceituosas" (Richard MISKOLCI, 2012, p. 25).

Tudo isso, porque essa marca à qual me refiro só foi possível porque, no decorrer dos anos de 1980, vários/as autores/as, pesquisadores/as e ativistas começaram positivar o termo que até então envolvia um menosprezo em relação, sobretudo a homossexuais masculinos, sustentados pelo argumento do que se pode chamar de ressignificação discursiva. Então, quando queer era atrelado à homossexualidade, por exemplo, a resposta não era de se repelir ao termo, mas abraçá-lo, justamente, porque, como afirmou Joshua Gamson (2002), o queer não é só se rebelar contra a condição marginal imposta pelas estruturas de poder, mas desfrutar desta condição. A ideia era de que não há nada de errado em materializar uma identidade que fosse queer no sentido abjeto da palavra, o errado era o lugar que a coletividade as ejetava, um lugar de não lugar. Essa é a crítica e grande problemática dos estudos Queer. Uma crítica contra a abjeção, diria Richard Miskolci (2012).

Esse pensamento de não assimilação foi força motriz para desconstruir o sentido negativo do termo por parte dos teóricos, que na visão de Judith Butler (2002), operava num sentido de fomentar uma prática linguística que degradava os sujeitos aos quais se referia. É nesse sentido que, para a autora, o termo atingia, antes da ressignificação, um poder ao carregar acusações, patologias, insultos. Em diálogo com Richard Miskolci (2012), entende-se que é por intermédio de um contraposicionamento que os movimentos queer nascem, pautando-se menos pela demanda de aceitação ou de incorporação coletiva e focando mais na crítica às exigências sociais, aos valores e às convenções sociais como forças autoritárias, preconceituosas. 
Enquanto que alguns dos chamados novos movimentos sociais, no decorrer da década de 1980 (quando aconteceu a emergência dos estudos queer) como o até então denominado movimento homossexual, de acordo com Richard Miskolci (2012), tinham como pauta a adaptação às demandas sociais, o queer, na contramão desse esforço, luta para mudar a sociedade de forma que ela Ihes seja aceitável. Desse modo, a crítica queer é uma crítica também contra a não assimilação de uma dita anormalidade à normalidade, isto é, a crítica queer é uma crítica contra toda e quaisquer formas hegemônicas de se pensar a identidade.

Em contrapartida, ao mesmo tempo em que o queer é uma crítica aos regimes adotados pelos (novos) movimentos sociais, como o movimento negro, os movimentos de mulheres e o movimento homossexual da década de 1960, é uma vertente que tem as reivindicações políticas dessas ações coletivas como nascente para a sua efervescência, pois esses movimentos na rubrica de novos foram os pioneiros, segundo Richard Miskolci (2012), a levar para o espaço público demandas que extrapolavam a dimensão econômica e a pontuar que as desigualdades sociais extrapolavam essa esfera, apontando, a partir do pensamento do autor, que a sexualidade, o desejo, o corpo, também eram mecanismos nos quais se estabeleciam relações de poder, hierarquias de dominação, disciplinamento de corpos.

O pensamento queer, segundo Richard Miskolci (2014), surge como uma proposta que entende a heterossexualidade como regime político-social que regula as vidas humanas, por meio de regulações sexuais e de gênero, que criam e sustentam desigualdades em todos os patamares da vida social, principalmente no não reconhecimento político e de direitos dos sujeitos fora da norma heterossexual e também cisgênera ${ }^{3}$ - é válido lembrar.

Queer, então, não é mais uma forma de ativismo colorido em defesa da homossexualidade. Queer é, nesse sentido, uma política pós-identitária na perspectiva de Guacira Lopes Louro (2001), simplesmente por encarar os regimes de normalização e apontar para o estranho, à

Cisgênera vem da palavra "Cisgênero" e é o oposto de Transgênero. Também pode ser representado pela abreviação cis. Pessoas Cis são pessoas que se identificam com o gênero que Ihes atribuíram no nascimento. 
contestação, para o que está fora do centro, por abarcar tudo o que se encontra em não lugar ou, em meias-palavras, por não se atrelar a identidades específicas como os movimentos de outrora. O Queer, diria, preocupa-se com aquilo que está nas margens e toda uma totalidade de corpos que não se pretendem ser assimilados ou entendidos enquanto diversidade, queer prega um aprendizado pela alteridade. Queer é diferença, desobediência.

O pensamento queer atinge status de teoria, quando Teresa de Laurentis, feminista italiana, ressignifica o termo em uma conferência nos Estados Unidos, de acordo com Richard Miskolci (2014), e o utiliza como um rótulo para abarcar um conjunto amplo e disperso de reflexões que questionavam o que Judith Butler (2003) passou a chamar de matriz heterossexual.

Mas é importante salientar que, apesar de possuir um direcionamento de crítica ou uma problemática específica, os estudos queer, como destacou Annamarie Jagose (1996) são uma categoria em processo de formação e isso não significa afirmar que a teoria ainda não tenha se solidificado ou assumido um perfil mais consistente, mas sim que sua definição de indeterminação, sua elasticidade, como propôs a autora, é uma de suas características constitutivas. Isso quer dizer que a teoria queer não é um campo cristalizado, com categorias prontas, acabadas como em algumas teorias sociais mais canônicas.

Dada essa situação, Annamarie Jagose (1996) adverte que pode parecer contraintuitiva, ou mesmo fútil, produzir um relato introdutório acerca do fenômeno queer, mas parte de sua eficácia política, segundo a autora, parte vem da influência semântica, como depende da sua resistência à definição e da forma que se recusa a apostar a sua reivindicação, tendo em vista que, conforme salienta David Halperin (1995, p. 113 apud Annamarie JAGOSE, 1996, p. 1), "quanto mais se torna uma disciplina acadêmica normativa, menos queer a teoria queer pode ser plausível de ser". Nesse sentido, não possui definição exata, mas representações em trânsito permanente.

A definição que mais afaga o que se tentou representar aqui é a que se enquadra no que Michel Foucault (2005) poderia perspectivar como saberes subalternos, frutos do que o autor chamara de reviravoltas 
do saber e que compreende blocos de saberes históricos que estavam presentes, porém disfarçados no cerne dos conjuntos funcionais e sistemáticos e que a crítica os faz ressurgir por meio da erudição. Em último lugar, por saberes sujeitados, o autor afirma que remonta séries de saberes que não são qualificados como saberes conceituais. São saberes, ingênuos, hierarquizados, saberes taxados com pouco nível de conhecimento e cientificidade. O queer surge assim, e é derivado desses saberes rasteiros, que vêm de baixo, das margens. É uma construção periférica de corpos periféricos que logra atingir um status quo e, talvez, por isso, quando entra nos espaços acadêmicos, é motivo de estranhamento das teorias que estão no cânone.

\section{DO QUEER À TEOLOGIA}

\subsection{Teologia gay e a percepção de um novo sujeito - o Gênesis}

Segundo Murilo Araújo (2012), a teologia queer é um ramo recente dentro dos estudos teológicos que começa a ser desenvolvido em meio às últimas décadas do século XX no contexto norte-americano e que se consolida, a partir dos anos 2000, na América Latina, principalmente por meio das contribuições do teólogo luterano André Musskopf.

Como já discutido, o termo queer empregou toda uma potencialidade negativa e mesmo sendo um enunciado performativamente ressignificado pelas teóricas e pelos teóricos ativistas, há que se reconhecer que a associação do termo à teologia causa certo espanto, sobretudo em meio a um contexto religioso em que as corporalidades que transitam fora da experiência sexual e de gênero imposta não são bem-vindas.

Dada essa situação, é quase que impossível pensar em uma vivência religiosa para tais corporalidades, mais complexo ainda é reconhecer o delineamento de uma teologia que atravesse ou parta das experiências pessoais das dissidências sexuais e de gênero, pois como bem salientou André Musskopf (2003) o dispositivo do armário além de atravessar a vida íntima de muitas pessoas não heterossexuais, também é útil - quase sempre - para atravancar o seu fazer teológico.

"Escondido, protegido, subversivo. Mistério, ocultamento, invisibilidade. A vida à meia luz é cheia de possibilidades e dilemas" (André 
MUSSKOPF, 2005, p. 2). É com essas palavras que André Musskopf inicia o seu À meia luz: a emergência de uma teologia gay, para afirmar que a realidade que circunda tais palavras demarca a experiência de pessoas não heterossexuais e aponta para uma reflexão acerca de seu discurso teológico.

Seria possível, então, uma vertente teológica que abarcasse essas reflexões? Em parâmetros teóricos, André Musskopf (2008) aponta positivamente que sim e que não se trata de um fenômeno relativamente novo, mas a um campo que emerge de uma genealogia de estudos que esteve em curso nos anos finais da década de 1980, inicialmente sendo chamada de teologia gay ou inclusiva, que, conforme André Musskopf (2003), articulava-se na perspectiva de mostrar e de exigir cidadania religiosa para indivíduos homossexuais, dentro de um contexto de ampla divulgação dos círculos de teologia da libertação e da segunda onda do movimento feminista.

Essa vertente teológica, semelhante às reivindicações dos movimentos GGGs de vanguarda propiciavam uma reflexão para se pensar um novo sujeito teológico, os homossexuais. Quase uma heresia. E a centralidade argumentativa para justificar essa força teológica herética, conforme Nash (apud André MUSSKOPF, 2005), era de que não há dúvidas: gays e lésbicas produzem teologia cristã desde a gênese da igreja. O que se pesa, nessa situação, é que suas experiências e corporalidades não foram classificadas como ponto de partida para reflexões teológicas. Isso significa dizer que, segundo Murilo Araújo (2012), não é que essas corporalidades sejam identidades novas no seio de uma teologia. São apenas experiências invisíveis; corpos historicamente periféricos, que, nessa vertente, apenas foram levados para o centro de um discurso teológico.

É assim que, consoante com André Musskopf (2003), a teologia gay, como nas comunidades eclesiais de base e nos grupos de mulheres, gays e lésbicas passaram a resgatar suas experiências, assim como suas formas de experimentar, ver e encarar o mundo, emergindo como sujeitos de sua própria realidade no confeccionar de sua história e no fazer de uma teologia que dê conta de suas vivências.

O empreendimento que as teólogas e teólogos gays lograram realizar, à luz de Murilo Araújo (2012), talvez tenha se constituído nas mais 
numerosas discussões entre a chamada Teologia da Libertação. Têm sido produzidas por meio das mais diversas perspectivas, sofrendo metamorfoses de modo significativo, ao passo das transformações sociais e na compreensão da própria sexualidade. Encontram bases na teologia da libertação, pois esta, conforme André Musskopf (2003), formula a emergência de novos sujeitos teológicos e também históricos, centrando-se agora nas relações sociais de exploração onde, como aponta Gutiérrez (apud André MUSSKOPF, 2005), os povos oprimidos sejam capazes de se expressar livremente e criativamente na sociedade e, entre o povo de Deus. É assim que a teologia gay emerge.

Assim como os movimentos homossexuais de vanguarda, como já discutido, tinham como bandeira a incorporação social em meio às normas de gênero e sexualidade, e um pensamento queer que problematizava tais normas (Richard MISKOLCI, 2012), tivemos, como pontua Murilo Araújo (2012), no desenrolar das perspectivas teológicas uma multiplicidade de posicionamentos apresentados sobre diversas rubricas: teologia homossexual, teologia gay, teologia inclusiva e a teologia queer, a que nos interessa. Por fim, tento apresentar uma crítica queer à teologia.

\subsection{Um estranho flanuear queer na teologia e as possibilidades deslocadas dessa aproximação}

Venho tentando até aqui apontar para as influências que culminaram no florescer de uma teoria queer. Mas afinal o que, de fato, pode o queer na teologia? Uma casual e estranha aproximação entre pensamento queer, desafiador, incerto, não acabado, instável e rebelde, e a teologia, um campo que historicamente se constituiu como um lócus disciplinador, normativo, um espaço onde se é privilegiado o regramento, a obediência às normas sexuais e de gênero. O desafio que circunda essa possível aproximação pode apontar que dela se desista, mas é na incerteza e brevidade da provocação que esse flanar talvez encontre a graça pelo risco.

Aposto na convicção dessa aproximação e, para ensaiar argumentação, reconsidero o queer - como já discutido - enquanto um conjunto de saberes e um posicionamento político, que promove crítica não 
necessariamente à posição daqueles e daquelas que estão dentro da norma sexual e de gênero, mas promove um questionamento no seio dessas próprias nuanças normativas que resultam em desigualdades. Do ponto de vista teológico, a teologia gay tentou problematizar a inserção das homossexualidades dentro de um discurso teológico que se sustenta com base nessas normas. Desse modo, uma primeira crítica queer à teologia estranharia o conformismo das possibilidades de incorporação no seio de um lócus hegemonicamente heteronormativo e ciscentrado. Assim, em uma associação entre ambos os campos, queer apontaria para a matriz estrutural que fomenta a reprodução das regulações de gênero e sexualidade sustentadas pelos discursos teológicos mais ortodoxos e até por uma teologia gay.

É de modo semelhante às críticas que o próprio movimento queer promove os movimentos homossexuais de vanguarda que André Musskopf (2003) abarca uma perspectiva queer. Para o autor, em uma ótica hermenêutica, as teologias gays construíam - e ainda quase sempre constroem - um trabalho interpretativo que se constituía no fito de rediscutir o que chama de textos de terror, isto é, as partes bíblicas que promovem ojeriza à homossexualidade. O erro dessas análises seria, segundo ele, o de não promover uma mirada ampla sobre as Escrituras sagradas em sua totalidade, então, o trabalho teológico hermenêutico que travam remonta em apenas tirar gays e lésbicas do armário no seio dos textos sagrados, e não contestar as pressuposições hetero-cis-centradas que fornecem as regulações de gênero e de sexualidade dentro dos próprios contextos de escrita dos textos sagrados.

Uma hermenêutica queer, penso, questionaria o seguinte: em que condições normativas foram escritas essas passagens e a Bíblia com um todo? Essas normas de gênero e sexualidade permitem um protagonismo a quem? Quais os efeitos da invisibilidade que produzem? Quais corporeidades são dignas em suas articulações e enquadramentos? Que corpos ela afeta? Por que travam uma utopia corporal homogeneizante e, por conseguinte, exterminam as possibilidades de diferença? Estas seriam algumas das indagações do queer em sua possibilidade de interpretação, que ouso apontar. 
Todos esses questionamentos desafiam uma ditadura heterossexual e cisgênera centrada nas bases estruturais de uma teologia normativa. Ao aproximar um flerte queer nesse campo em análise, automaticamente autoriza-se alargar as possibilidades de sexualidades, de gêneros e de identidades para além das caixas que tal vertente teológica historicamente tem empregado. Novas percepções são jogadas no altar de uma experiência teológica, em suas possibilidades corpóreas e práticas. Um flâneur queer na teologia permite compreender novas éticas e estéticas sexuais que, na verdade, não são novas, apenas passam a ser colocadas no centro das discussões e não mais nas possibilidades de higienização e de repelência que se esquadrinham historicamente nos confessionários, nos bancos, nas práticas discursivas.

Aliás, tentar passear com o queer em uma crítica teológica emprega reconhecer toda uma multiplicidade de corpos e não apenas as homossexualidades masculinas e femininas, como tem se pensado em alguns trabalhos, nos quais se reconhece teologia queer enquanto sinônimo de uma teologia estritamente gay, como aponta Coelho Junior, ao dizer que a "teologia queer surge com a preocupação de responder a vivência de pessoas gays" (Carlos Lacerda COELHO JUNIOR, 2012, p. 10). Queer é não definição identitária, como já entendemos, logo, falar que teologia queer é teologia para pessoas homossexuais é altamente perigoso. Uma teologia que abrace o queer enquanto posição teórico-metodológica deve assumir o afago de tudo aquilo que está fora da norma e o que se encontra em regiões periféricas não é só a homossexualidade, uma manifestação da sexualidade humana. E o gênero? E os corpos que desafiam e materializam ruptura com as utopias projetadas a ele, o gênero? Os transcorpos não falam?

Portanto, não dá para transitar um pensamento queer nos discursos teológicos pensando esse trânsito só como um politizar de viados e de sapatões, pois essa teoria desloca-se para além dessas vivências e questiona a matriz problematizada por Judith Butler (2003), que impõe noção de coerência entre os binários sexo/gênero, prática sexual/ desejo. Apontar para esse caminho que questiona o espaço só das homossexualidades em um discurso teológico é (re)embarcar por livre e espontânea vontade em uma caravela com os colonizadores, sabendo 
que uma gama de possibilidades corpóreas será novamente escravizada com essa ação. É fazer com que se reconheça o queer na teologia como outrora: apenas mais uma bandeira de ativismo colorido que se repete na História.

Aqui, já é possível encontrar alguns elementos para promover uma peregrinação queer e os seus impactos na teologia, pelo menos em nível de discurso teórico. Os caminhos ou os métodos que essa articulação emana não estão prontos, são distintos e aqui se correu o risco de promover um queer menos queer do que se poderia projetar, mas, de qualquer forma, há que se reconhecer que essas iniciativas, mesmo que distribuídas geograficamente de formas aleatórias entre os diversos campos do saber, vêm produzindo alguns efeitos. Todavia, é questionável dizer que queer pode revolucionar o modo de se fazer teologia, mas se surte ou preconiza possibilidades de lugar para corporalidades subalternas, ainda que de forma tímida, esse affair não pode ser vilipendiado.

Por um lado, não posso deixar escapar um refluxo paradoxal problemático nessa tentativa de flanuagem queer na teologia - e é importante reconhecer tal fato: ainda que o pensamento queer concentre-se em perspectivas de desconstruir e de reconstruir a forma como os discursos teológicos se deixam escapar das dissidências sexuais e de gênero, por outro lado, as instituições oficiais que lidam com teologia adotam um panorama que enquadra as corporeidades a partir das normas sexuais e de gênero, adotam a obediência.

As dificuldades para propor uma mudança nessa subserviência teológica a um pilar hetero-cis-centrado respingam fortemente no dispêndio de se pontuar um queer em estradas teológicas e colocam as respectivas questões que encerram este ensaio: como se emprega um pensamento queer na prática e realidade teológica na vida real e não nas páginas de periódicos? O que posso fazer com o queer em salas de aula, sobretudo em programas de pós-graduação em Ciências da Religião e Teologia? Como é que o queer pode entrar na grade curricular dessas áreas do conhecimento, muitas vezes tão engendradas em vivências e teorias normativas?

Talvez, ou pelo menos em parte, as respostas para essas indagações 
se coloquem na reluta em pontuar incisivamente o que lembrou Douglas Conceição (2006), que o campo das ciências da religião é múltiplo em seu ponto de vista teórico-metodológico. O passeio do queer pela teologia e nas Ciências da Religião pode entrar por essa brecha e possibilitar que uma gama de corporeidades possa não só sair do armário, mas destruí-lo.

\section{REFERÊNCIAS}

ARAÚJO, Murilo Silva de. Mãe monstra, rogai por nós: sexualidades queer e presença religiosa no projeto messiânico da era "Born this way", de Lady Gaga. In: Seminário Internacional Fazendo Gênero 10 (Anais Eletrônicos), Florianópolis, 2012. ISSN 2179-510X. BUTLER, Judith. Cuerpos que importan. Sobre los límites materiales y discursivos del "sexo". Buenos Aires: Paidós, 2002.

BUTLER, Judith. Problemas de gênero: feminismo e subversão da identidade. Tradução

- Renato Aguiar. Rio de Janeiro: Civilização Brasileira, 2003.

BUTLER, Judith. Quadros de Guerra: quando a vida é passível de luto. Rio de Janeiro: Civilização Brasileira, 2015, 288p.

COELHO JUNIOR, Carlos Lacerda. A emergência de uma teologia queer - uma breve análise sobre as influências do movimento feminista e homossexual no processo de reconfiguração do sagrado. $17^{\circ}$. Encontro Nacional da Rede Feminista e Norte e Nordeste de Estudos e Pesquisa sobre a Mulher e Relações de Gênero, Brasil, dez. 2012. Disponível em: <http://www.ufpb.br/evento/lti/ocs/index.php/17redor/17redor/paper/ view/114>. Data de acesso: 26 jul. 2017.

COELHO JUNIOR, Carlos Lacerda. "Somos as ovelhas coloridas do senhor": uma análise sociológica acerca da vivencia homossexual em uma igreja inclusiva. Universidade Federal de Alagoas. Instituto de Ciências Sociais. Programa de Pós-graduação em Sociologia. Maceió, 2014.

CONCEIÇÃO, Douglas Rodrigues da. A religião em cena: perspectivas de investigação. Belo Horizonte, v. 9, n. 23, p. 833-896, out./dez. 2011 - ISSN: 2175-5841.

DESCARRIES, Francine. A contribuição das mulheres à produção de palavras e saberes. In: Estudos feministas, N. especial 94. Florianópolis, 1993, p. 57-64.

FACCHINI, Regina. "Sopa de letrinhas"?: movimento homossexual e produção de identidades coletivas nos anos 90: um estudo a partir da cidade de São Paulo, 2002, 241 p. FOUCAULT, Michel. Em defesa da Sociedade: curso no Collège de France (1975-1976). Martins Fontes, São Paulo, 2005.

FOUCAULT, Michel. História da sexualidade: a vontade de saber. Vol. I. Rio de Janeiro: Edições Graal, 1988. 
FOUCAULT, Michel. Vigiar e punir: nascimento da prisão; tradução de Raquel Ramalhete. Petrópolis: Vozes, 1987, 288p.

FRY, Peter. Da hierarquia à igualdade: a construção histórica da homossexualidade no Brasil. In: FRY, Peter. Para inglês ver: identidade e política na cultura brasileira. Rio de Janeiro: Zahar, 1982, p. 87-115.

GAMSON, Joshua. Deben autodestruirse los movimientos identitarios? Un extraño dilema. In: JIMÉNEZ, Rafael M. Mérida. Sexualidades transgresoras. Una antología de estudios queer. Barcelona: Icária editorial, 2002, p. 141 a 172.

GOFFMAN, Erving. (1975). Estigma: notas sobre a manipulação da identidade deteriorada. Márcia Bandeira de Mello Leite Nunes (Trad.). Rio de Janeiro: LTC

HARAWAY, Donna. Manifesto Ciborgue: ciência, tecnologia e feminismo socialista do final do século XX. In: TADEU, Tomaz; KUNZRU, Hari; HARAWAY, Doona (Org). Antropologia Ciborgue: as vertigens do pós-humano, 2. ed. Belo Horizonte: Autentica Editora, 2009. JAGOSE, Annamrie. Queer Theory: an introduction. New York University Press. Washington Square. New York. 1996. Disponível em: https://drive.google.com/drive/folde rs/oB3J08f6XX1LdbFR5RUgLT2dmQoE. Acesso em 22 jun. 2017.

LOURO, Guacira Lopes. Conhecer, pesquisar, escrever. In: Educação, Sociedade e Culturas, n. 25, 2007, p. 235-245. Disponível em: https://drive.google.com/drive/folders/oB 3J08f6XX1LdR1dvTEM5OGI5Q0E Acesso em: 28 jul. 2017.

LOURO, Guacira Lopes. O “estranhamento” Queer. In: Fazendo gênero. Simpósio temático: A violência Material e Simbólica, 2006.

LOURO, Guacira Lopes. Teoria Queer: Uma Política Pós-Identitária para a Educação. In: Revista Estudos Feministas, v. 9, n. 2. Florianópolis: IFCH, 2001.

MISKOLCI, Richard. Estranhando as Ciências Sociais: notas introdutórias sobre teoria queer. Dossiê Teoria Queer. In: Revista Florestan. UFSCar. Ano 01 - número 02 - novembro/2014. ISSN 2357-8300.

MISKOLCI, Richard. Não ao sexo rei: da estética da existência foucaultiana à política queer. In: FRACISCO DE SOUSA, Luis Antônio. SABATINE, Thiago Teixeira. MAGALHÃES, Bóris Ribeiro de. (Org.). Michel Foucault: sexualidade, corpo e direito. Marília: Oficina Universitária. São Paulo: Cultura Acadêmica, 2011. p. 47-68.

MISKOLCI, Richard. Teoria Queer: um aprendizado pelas diferenças. Belo Horizonte: Autentica Editora, 2012.

MUSSKOPF, André Sidnei. À meia luz: a emergência de uma teologia gay: Seus dilemas e possibilidades. Cadernos IHU Ideias. São Leopoldo, ano 3, n. 32, p. 1-34, 2005 a.

MUSSKOPF, André Sidnei. A Teologia que sai do armário - um depoimento teológico. Impulso, Piracicaba, 14 (34): 129-146, 2003.

MUSSKOPF, André Sidnei. Via(da)gens teológicas: itinerários para uma teologia queer no Brasil. São Leopoldo: EST/PPG, 2008. 
OLIVEIRA, Pedro Paulo de. Discursos sobre a Masculinidade. Estudos Feministas, Florianópolis, v. 6, n. 1, p. 91, jan. 1998. ISSN 0104-026X. Disponível em: https://periodicos. ufsc.br/index.php/ref/article/view/12036. Acesso em: 10 jun. 2017.

PELÚCIO, Larissa. Breve história afetiva de uma teoria deslocada. Dossiê Teoria Queer. In: Revista Florestan. UFSCar. Ano 01 - número 02 - novembro/2014. ISSN 2357-8300. PERROT, Michelle. Minha história das mulheres (Tradução: Angela M.S. Correa). São Paulo: Contexto, 2007.

PRECIADO, Paul Beatriz. Multidões queer: notas para uma política dos "anormais". Estudos Feministas, Florianópolis, v. 19, n. 1, p. 11, jan. 2011. ISSN 1806-9584. Disponível em: https://periodicos.ufsc.br/index.php/ref/article/view/S0104-026X2011000100002/18390 Acesso em: 26 jul. 2017.

RAGO, Margareth. Epistemologia feminista, gênero e história. In: PEDRO, Joana Maria; GROSSI, Miriam Pillar (Orgs.). Masculino, feminino, plural: Gênero e interdisciplinaridade. Florianópolis: Ed. Mulheres,1998, p. 1-17.

RAGO, Margareth. Epistemologia feminista, gênero e história: Descobrindo historicamente o gênero. Coordenação: Secretaria de Imprensa e Comunicação. CNT-Compostela, 2012. ISBN: 978-84-92428-63-2.

SCOTT, Joan. "Gênero: uma categoria útil de análise histórica". Educação \& Realidade. Porto Alegre, vol. 20, n. 2, jul./dez. 1995. Disponível em: http://www.observem.com/up load/935db796164ce35091c80e10df659a66.pdf. Acesso em 12 jun. 2017.

Submetido em: 3-10-2017

Aceito em: 25-11-2017 